\title{
Increasing rejection in microfiltration using vibrating membrane
}

\author{
Asmat Ullaha ${ }^{\mathrm{a},}$, Kamran Alam ${ }^{\mathrm{b}}$, Saad Ullah Khan ${ }^{\mathrm{b}}$ and Victor M Starovc,, \\ aDepartment of Chemical Engineering, University of Engineering and Technology Peshawar, \\ Pakistan \\ bFaculty of Materials and Chemical Engineering, GIK Institute of Engineering Sciences and \\ Technology, Topi, Pakistan \\ cDepartment of Chemical Engineering, Loughborough University, UK \\ * Correspondence: E-mail address: a.ullah@uetpeshawar.edu.pk, v.m.starov@lboro.ac.uk
}

\begin{abstract}
A new method is proposed to increase rejection in microfiltration by applying membrane oscillation using a new type of microfiltration membranes with slotted pores. The oscillations applied to the membrane surface result in reducing membrane fouling and increasing separation efficiency. An exact mathematical solution of the flow in the surrounding solution outside the oscillating membrane is developed. The oscillation results in appearance of the lift velocity, which moves oil particles away from the membrane. The latter results in both reducing membrane fouling and increasing oil droplets rejection. This developed model was supported by the experimental results for oil water separation in produced water treatment. It was proven that oil droplet concentration reduced notably in the permeate due to the membrane oscillation and that applied shear rate caused by the membrane oscillation is also reduce pore blockage. New generation of microfiltration membranes with slotted pores was used in the experiments.
\end{abstract}

Keywords: Membrane oscillation; shear rate; slotted structure membrane; oil water separation and membrane fouling

\section{INTRODUCTION}

Sea water is substantially polluted by the discharge of oily produced water, which is an essential environmental concern [1-4]. On industrial scale, oily produced water is generated in huge amount with prediction of approximately 88 billion barrels on the yearly basis worldwide [5]. There are various separation methods used for purification of the oily produced water which include $\mathrm{pH}$ change, gravitational method, centrifugation, biological treatment, membrane filtration and electrostatic de-emulsification [1, 6-12]. Membrane purification process is superior over other processes because it has several benefits such as it require no chemicals, low input energy, environment friendliness, high quality of permeate [11,13-16]. It is the reason why membrane separation processes got attention of researchers over recent years for treatment of produced water $[17,18]$. Despite of wide application of membrane purification, fouling is the major problem in membrane separation of oil from water emulsion that leads towards a considerable reduction in the permeate flux $[11,19]$. 
Various methods of membrane separation have been tried for the separation of oil droplets and water. The method of microfiltration (MF) [2026] and ultrafiltration (UF) [27-32] are considered superior as compared to other membrane separation methods for separation of oil from water. The reason behind that is fouling in these membranes is less than that of reverse osmosis and nano-filtration membranes for oil water separation. It has been found that MF membrane gives greater permeate flux at lower trans membrane pressure as compared to UF process.MF is more economical for oil water separation on commercial scale [33-35].Various researchers have also studied the impact of membrane pore geometry on separation efficiency [36-39]. Recently slotted pore membranes were introduced for oil water emulsion purification $[24,35,40-44]$. It was found that slotted pore membrane gives greater value of permeate flux at less trans-membrane pressure compared to circular pore membrane [35].

MF is widely used, however, the membrane fouling still remains the important issue to be resolved [44]. Various methods have been suggested for the reduction of the membrane fouling of increasing shear such as higher cross flow filtration and aeration. In the aeration process, bubbles are generated which results in disturbing the concentration polarization and, hence, reducing the fouling [45]. However, this process has disadvantage of higher energy consumption. In the case of cross-flow filtration, feed supplied with high tangential velocity, which results in shear rate generation over the membrane surface [46], but this approach has also limitation of high power consumption and requires multiple recirculation of feed stream [46,47]. To overcome this problem of higher energy consumption in cross flow filtration, another method referred to as dynamic microfiltration was proposed. In dynamic microfiltration, relative motion between the bulk fluid and membrane used is applied, which results in higher shear rate applied to the membrane surface. This is achieved by vibration or rotation of the membranes. Application of membrane oscillation, fouling and concentration polarization can be reduced [48-58] and just this method is considered below. It is shown below that the membrane oscillation results in a substantial decrease of the trans-membrane pressure, results in a higher rejection of oil droplets and decreases substantionly membrane fouling. It is shown below that membrane oscillation method provides lower oil concentrations in the permeate, that is, higher rejection as compared with other memthods.

Mathematical model is developed below and exact solution of the flow in a vicinity of the oscillating membrane is deduced. The deduced mathematical solution allows calculating the shear applied on the membrane surface. It is shown that the imposed oscillations allow reduce membrane fouling and increase rejection of oil droplets, which is caused by lift velocity. It was shown that because of the oscillation, which are applied over the membrane's surface, lift velocities are developed, which move the droplets from the membrane's surface. The effect of membrane pore blocking was studied at various shear rate. Experimental investigation of the oscillating membrane fouling is undertaken, which is an agreement with the theoretical prediction. The prediction of permeate concentration of oil droplets was made.

A new type of membrane with slotted pores was used for investigation of oscillation influence, which were not used for this purpose before. 


$$
\frac{\partial V_{z}}{\partial t}=v\left(\frac{\partial^{2} V_{z}}{\partial y^{2}}\right)
$$

$\mathrm{Z}(\mathrm{t})=\mathrm{A} \sin (\omega \mathrm{t})$

$\mathrm{V}_{\mathrm{z}}=\mathrm{A} \omega \cos (\omega \mathrm{t}), \mathrm{y}=0$,

At $\mathrm{y} \rightarrow \infty$

\section{MATHEMATICAL MODEL}

In Figure 1 a schematic diagram of the membrane oscillating along zaxis is presented. The velocity distribution was generated because of oscillating membrane, which results in the shear rate creation. The oscillation results in a lift velocity of the oil droplets, which moves away the fouling materials from surface of membrane and reduce the concentration polarization in the vicinity of the membrane. As a result, both fouling and concentration polarization are reduced. The model is developed in this section allows calculating the shear rate over the membrane's surface caused by membrane oscillations. The dimension of the membrane module is supposed much bigger as compared with the dimension, $\boldsymbol{\delta}$, of the region caused by the oscillations (Figure 1), hat is, the membrane can be assumed to be flat. The oscillating membrane is completely immersed in the liquid. It is assumed also that the Reynolds number is small. In this case Navier-Stokes equations are reduced to only one equation:

\section{(1)}

where, $\mathrm{V}_{\mathrm{z}}$ is $\mathrm{z}$ component of the fluid velocity, which depends on the $\mathrm{y}$ only (Figure 1), $\mathrm{t}$ and $\mathrm{y}$ are time and co-ordinate (Figure 1), $v$ is a kinematic liquid viscosity. The displacement of membrane which is oscillating along $\mathrm{z}$-axis is as follows (Figure 1):

where A is an amplitude of oscillations and $\omega$ is the frequency of oscillations.

The following boundary conditions should be satisfied for the liquid velocity, determined by Eq. (1):

$$
\mathrm{V}_{\mathrm{z}} \rightarrow 0, \mathrm{y} \rightarrow \infty
$$

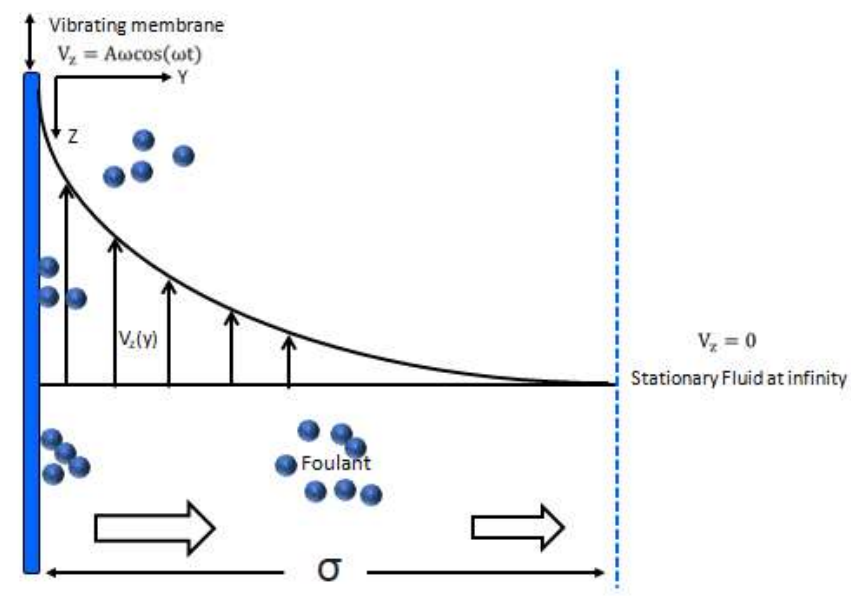

Figure 1. Velocity distribution of fluid \& motion of foulants in the vicinity of submerged oscillating membrane. 
Exact solution of Eq. (1) satisfying boundary conditions (2)-(3) is as follows:

$V_{z}=A \omega \exp (-\alpha y) \cos (\alpha y-\omega t)$,

where $\alpha=\sqrt{\omega / 2 v}$. See Appendix for details of the derivation.

According to Eq. (4) the influence of oscillations is extended into the bulk of the liquid on the distance $\delta \sim \frac{1}{\alpha}=\sqrt{2 v / \omega}$, that is, decreases with increasing frequency of oscillations.

We define the shear rate as $\gamma(\mathrm{t}, \mathrm{y})=\frac{\mathrm{dv}_{\mathrm{z}}(t, y)}{\mathrm{dy}}$. Using Eq. (4) we conclude:

$\gamma(\mathrm{t}, \mathrm{y})=\frac{\mathrm{dV}_{\mathrm{z}}(t, y)}{\mathrm{dy}}=-A \omega \alpha \exp (-\alpha y)[\cos (\alpha y-\omega t)+\sin (\alpha y-\omega t)]$

The shear rate over the surface of the oscillating membrane can be obtained by finding the value for boundary at $y=0$. This gives the shear rate over the surface of the oscillating membrane:

$\gamma_{\mathrm{s}}=A \omega \alpha \quad[\sin (\omega t)-\cos (\omega t)]$

The shear applied on the membrane surface is proportional to the frequency of oscillations according to Eq. (6). This shear rate prevents pore blocking. The latter has a direct experimental confirmation (see Figure 7), which proves that pore blocking is reduced linearly with oscillation frequency in accordance with Eq. (6). In the absence of the oscillations, the only force acting on the oil droplet is the drag force, which pushes the droplet through the membrane into the permeate. However, when the membrane is oscillating this results in generation of the shear of various intensities and the lift force, which moves the oil droplet away from the membrane surface. Figure 2 shows the act of forces (drag and lift forces) in the case of membrane oscillation. Lift force is the consequence of the applied oscillations of the membrane surface. The intensity of the lift force is higher at the membrane surface and gradually decreases when moving away from the membrane surface. 


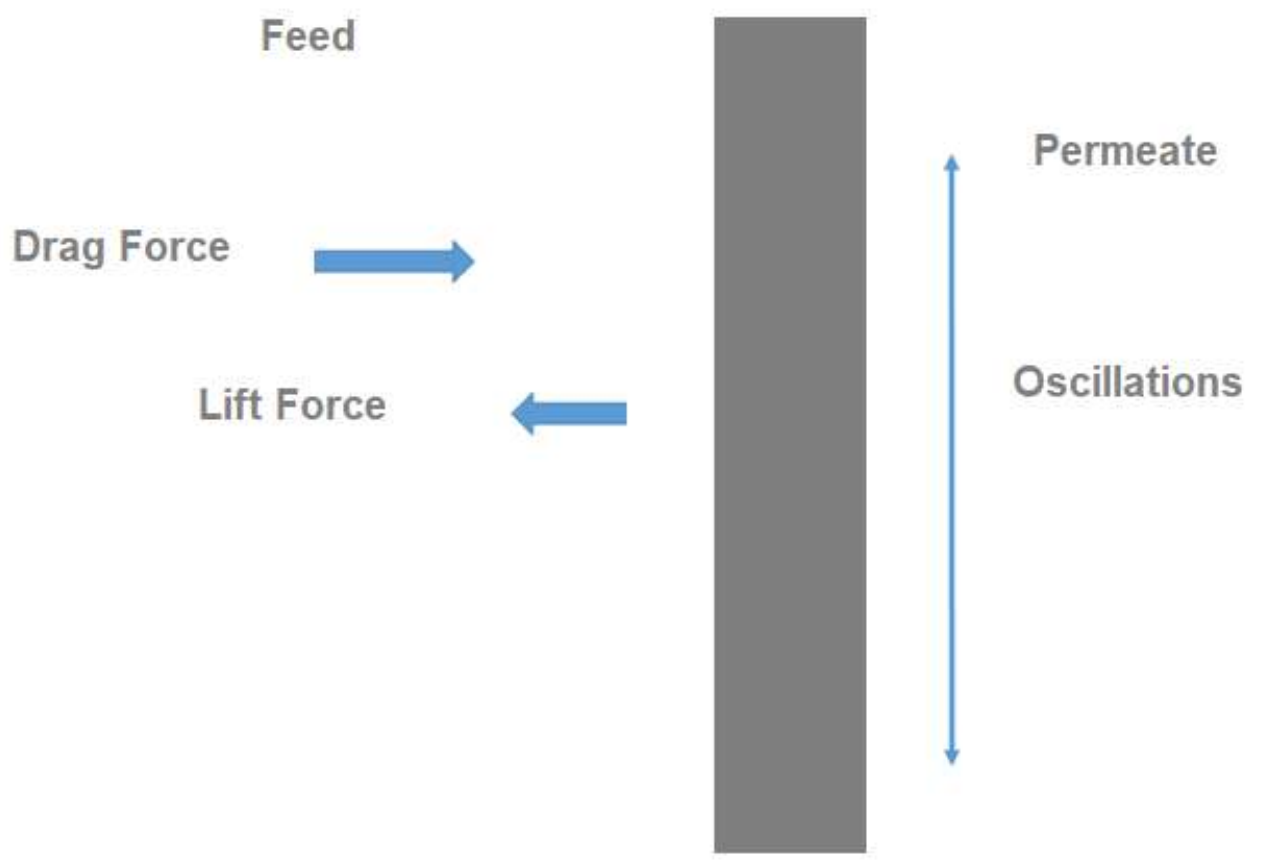

Oscillating Membbrane

$F_{d}=k_{w} 12 \pi \eta R_{s p} U$

$F_{l}=81.2\left(\left(\rho_{w} \eta|\gamma|^{3}\right)^{0.5}\right) R_{s p}{ }^{3}$,
Figure 2. Drag force tries to push the drops to the permeate side, while the lift force comes from the membrane oscillation acts in the opposite direction to the drag force.

Expressions for the drag force and lift force are given below:

where $F_{d}$ is the drag force, $k_{w}$ is a wall correction factor, for a similar system $k_{w}$ value 4.3 was used [24]; $\eta$ is the dynamic viscosity of the liquid, $R_{s p}$ is the radius of the droplet and $U$ is the permeate velocity of the liquid, caused by applied cross-membrane pressure difference [24].

The lift force is given by the following expression [46]:

where $\mathrm{F}_{1}$ is the lift force, $\rho_{w}$ is the density of the water at room temperature and $\gamma$, according to Eq. (6), is the applied shear rate [46]. Eq. 8 shows the lift force is determined by the applied shear rate and drop size. It means that for a given shear rate, the shear force will be more effective for larger droplets [46]. Note, according to Eqs. (6) and (8) the lift force decreases exponentially away from the oscillation membrane surface.

The shear rate is produced over the surface of membrane because oscillation creates the lift force which tends to move the droplets from the surface of membrane. As a result, number oil drops which could be deposited 
on the membrane surface and block membrane pores is reduced. So, fouling also gets reduced. The model is validated with the experimental results in the following section. It is shown below the less concentration of oil droplets in permeate stream, which is due to the shear rate applied over the membrane surface.

(9)

According to Figure 2 the drag velocity of oil droplets towards the oscillating membrane is reduced (or even becomes negative, that is, away from the oscillating membrane), which is caused by the applied membrane oscillations.

\section{EXPERIMENTAL METHODOLOGY}

OSCILATING MEMBRANE FILTRATION

The food blender at high speed was used for the oil droplets formation from vegetable oil. The real produced water was also used in the experiments. The Coulter Mullisizer II was used for the examination of oil droplets size distribution in both cases. Size scale of oil droplets in both cases was determined in the range of $1 \mu \mathrm{m}$ to $15 \mu \mathrm{m}$. The slotted porous membrane of $4 \mu \mathrm{m}$ pore size in width was utilized for the process of oil and water separation (Figure 3). This membrane was made up of Nickel (Ni) whose surface was modified with Poly tetra fluoro ethylene (PTFE) by Micropore Technologies, UK. The picture of membrane was captured by scanning electron microscopy shown in Figure 3.

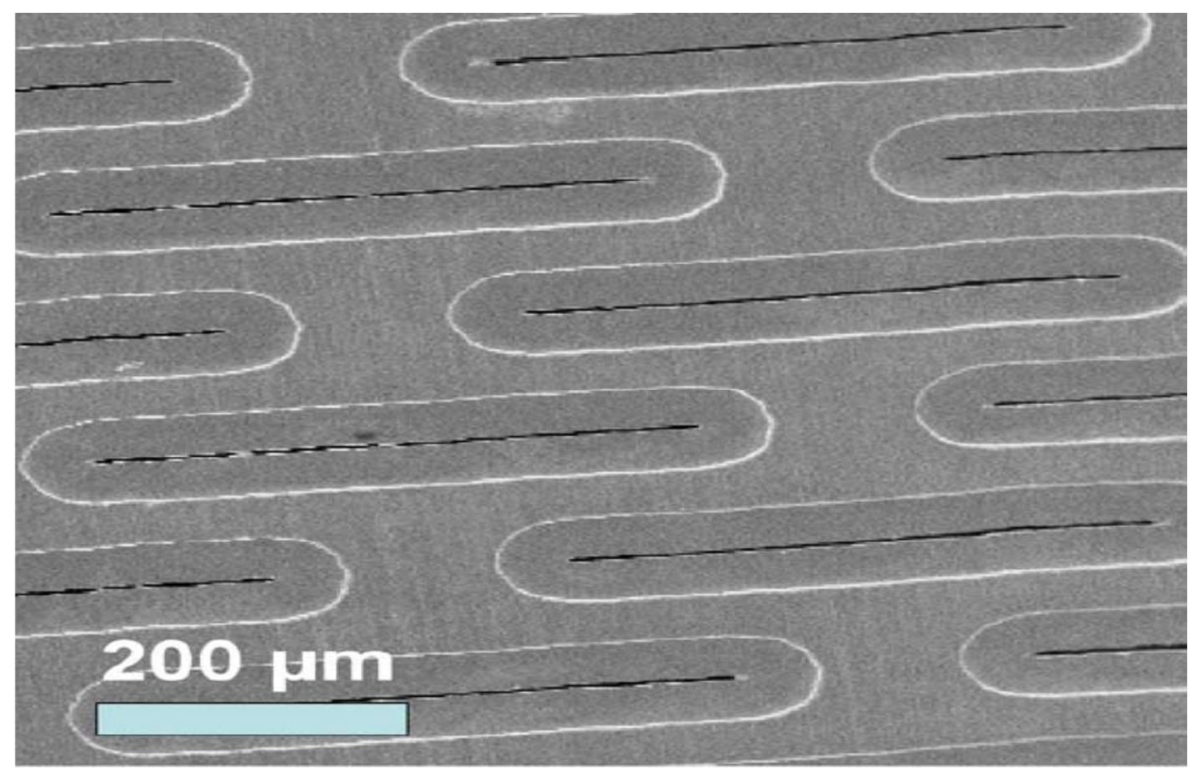

Figure 3. Scanning Electron Microscopy (SEM) Diagram for Slotted Porous Structure Membrane.

The membrane was connected with oscillating arm, then oscillating arm is initiated with electrochemical oscillator in order to create shear rate over the membrane surface. The flow diagram of oscillating microfiltration membrane with oscillating system for separating oil and water is shown in Figure 4 . The oscillating frequency and amplitude scale for membranes was 
varied in between 0 to $10 \mathrm{~Hz}$ and 0 to $10 \mathrm{~mm}$, respectively. As a result, the shear rate was produced in the vicinity of the membrane outer surface. The constant flux through the membrane was created using positive displacement (PD) pump.

Filtration experiments with the oscillating sotted pore membrane at various intensities were applied to both crude oil and vegetable oil emulsions. The membrane oscillation in vertical direction results in the shear rate creation.

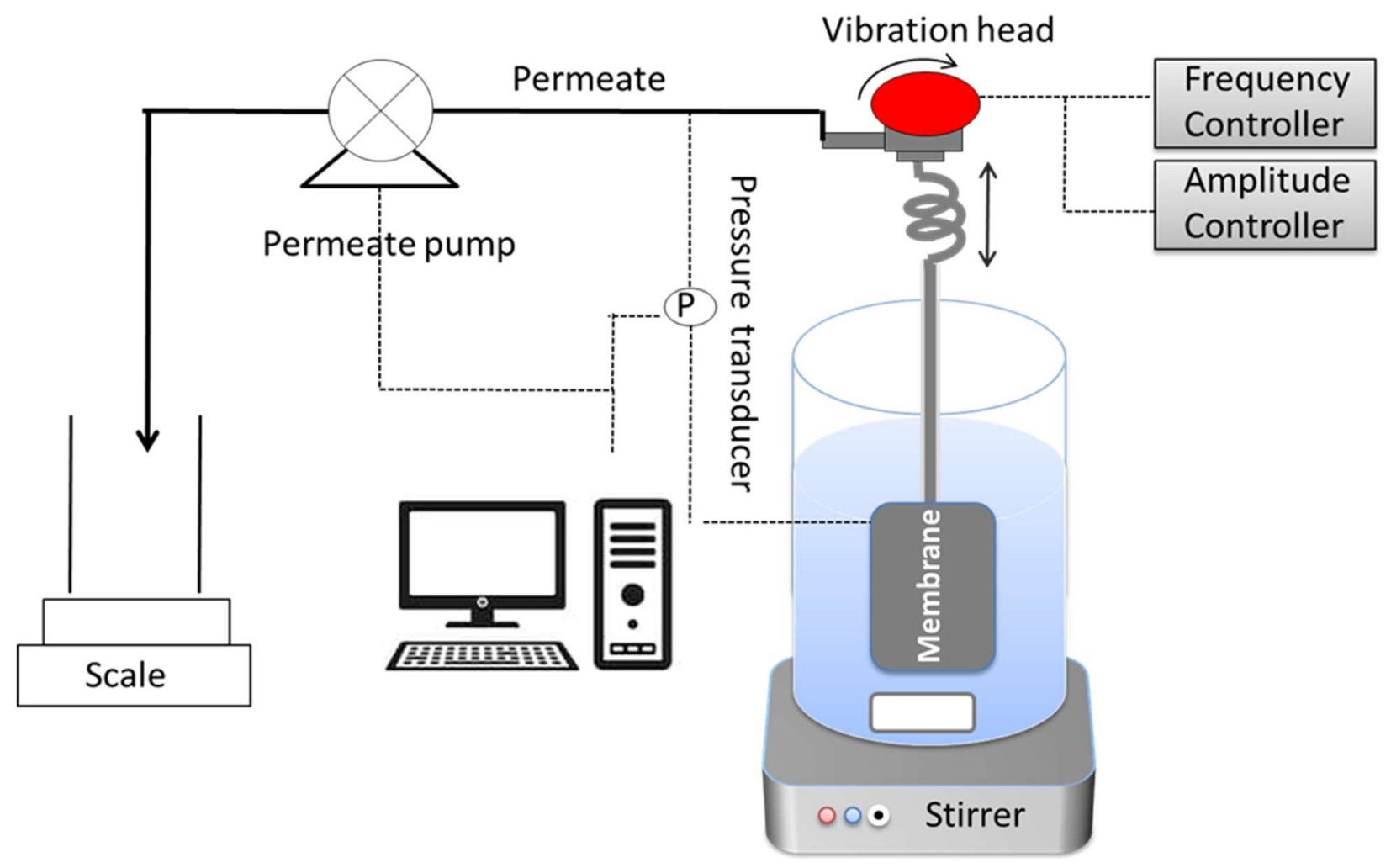

Figure 4. Flow diagram of the membrane oscillation devise.

\section{MATERIALS USED}

The drops of crude oil and vegetable oil (stabilized by Tween 20) were used. In both cases oil droplets showed the interfacial tension around 30 and $4 \mathrm{mn} / \mathrm{m}$, accordingly. The length and width values of slotted pores on the membrane surface were $400 \mu \mathrm{m}$ and $4 \mu \mathrm{m}$, respectively. The total area of the slotted pre membrane was $1.6 \times 10^{-9} \mathrm{~m}^{2}$.

\section{RESULTS AND DISCUSSION}

The size distribution is established based on oil droplets mass in the permeate stream shown in Figures 5 and 6. Figures 5 and 6 show that there is a considerable reduction in the concentration of oil droplets in permeate caused by membrane oscillations are applied. The reduction in concentration of permeate was found to be a linear function of applied shear rate. The interfacial tension has played as an important part to reduce the oil droplets concentration. At low value of interfacial tension, flattening and deformation 
of oil droplets was easier, which tends to move droplets into the permeate. While at high value of interfacial tension, the droplets became stiffer, their deformation and flattening was not so easy and this results in a lower droplet penetration into the permeate.
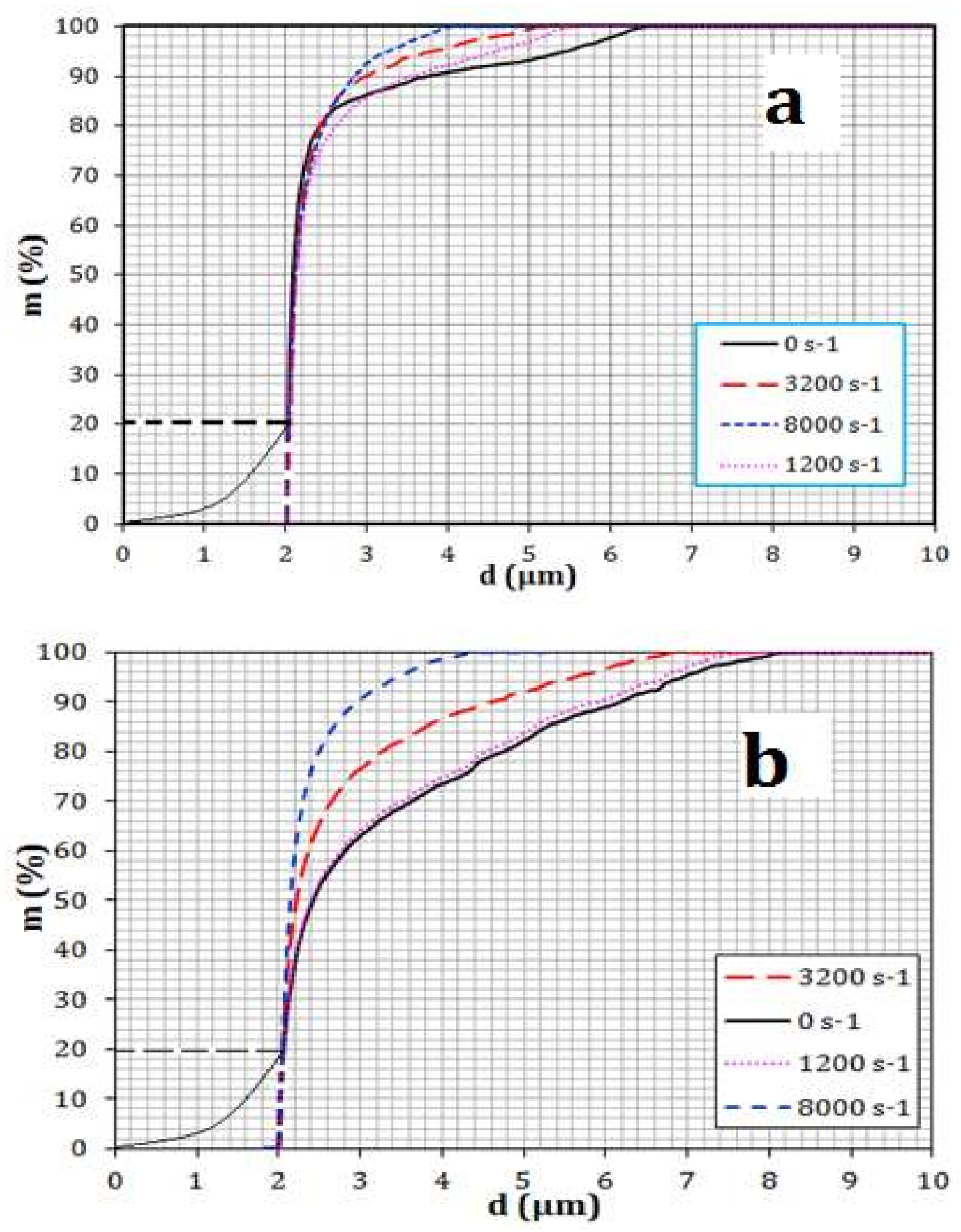

Figure 5. Size Distribution of mass of oil droplets stabilized by Tween 20 in the permeate at (a) at $200 \mathrm{l} / \mathrm{m}^{2} \mathrm{~h} . \&(b) 1,000 \mathrm{l} / \mathrm{m}^{2} \mathrm{~h}$. [44]. 

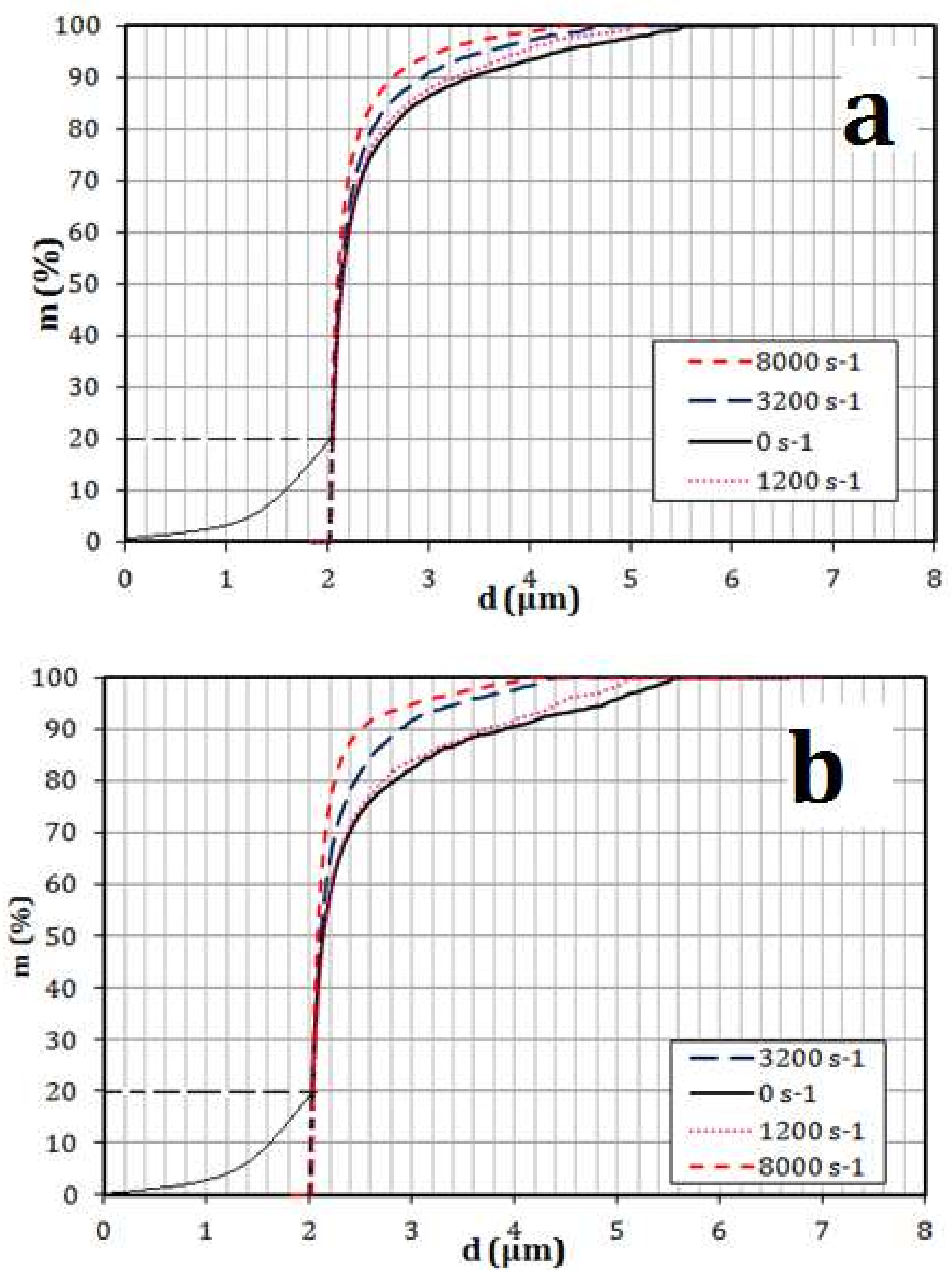

Figure 6. Size distribution of mass of crude oil droplets in the permeate at (a) 200 $\mathrm{lm}^{2} / \mathrm{hr}$ (b) $1000 \mathrm{l} / \mathrm{m}^{2} \mathrm{~h}[44]$.

The blocking of pores (slots) of membrane was investigated experimentally by applying oscillation shear rate over the membrane surface. In these experiments, droplets of crude oil and vegetable oil (stabilized by Tween 20) were used. Like concentration in permeate, it was found that blockage of membrane pores were also reduced by applied oscillating 
membrane. It was found that the blockage of pores was appreciably reduced by oscillations applied as shown in Figure 7. This reduction in blockage was found to be a linear function of oscillating frequency of membrane. It means the greater value of oscillating frequency of the membrane, the lower blockage of pores is. It was shown that the interfacial tension was essential parameter in pores blockage of membrane. Oil droplets having low interfacial tension can be deformed easily and tends to move into the permeate, which results in less pore blockage. But on the other side, at high interfacial tension, blockage in pores of membrane was found higher. This made the drops stiffer and it became more difficult to push the undeformed drops through pores, which results in more pore blockage [44].

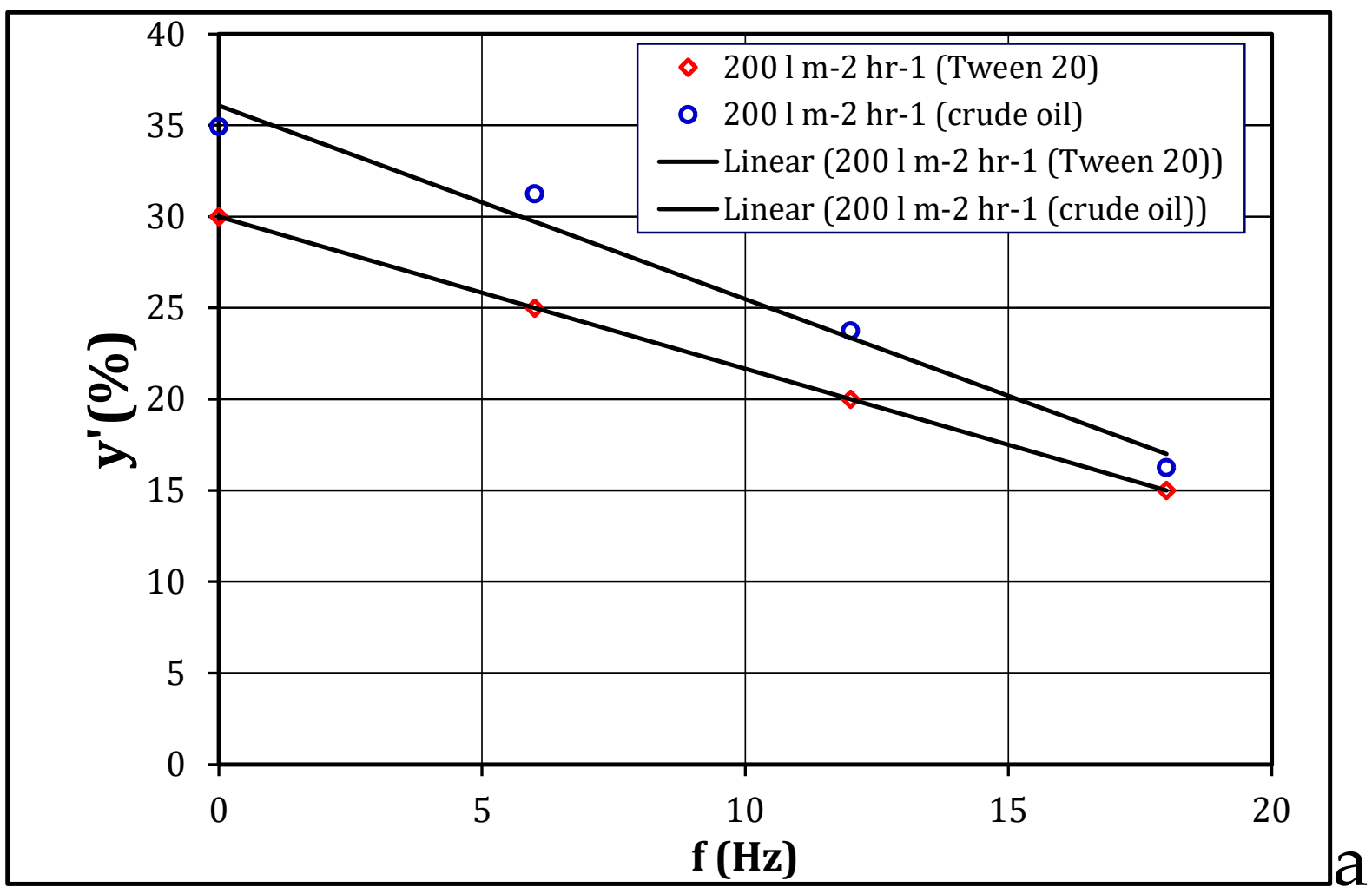




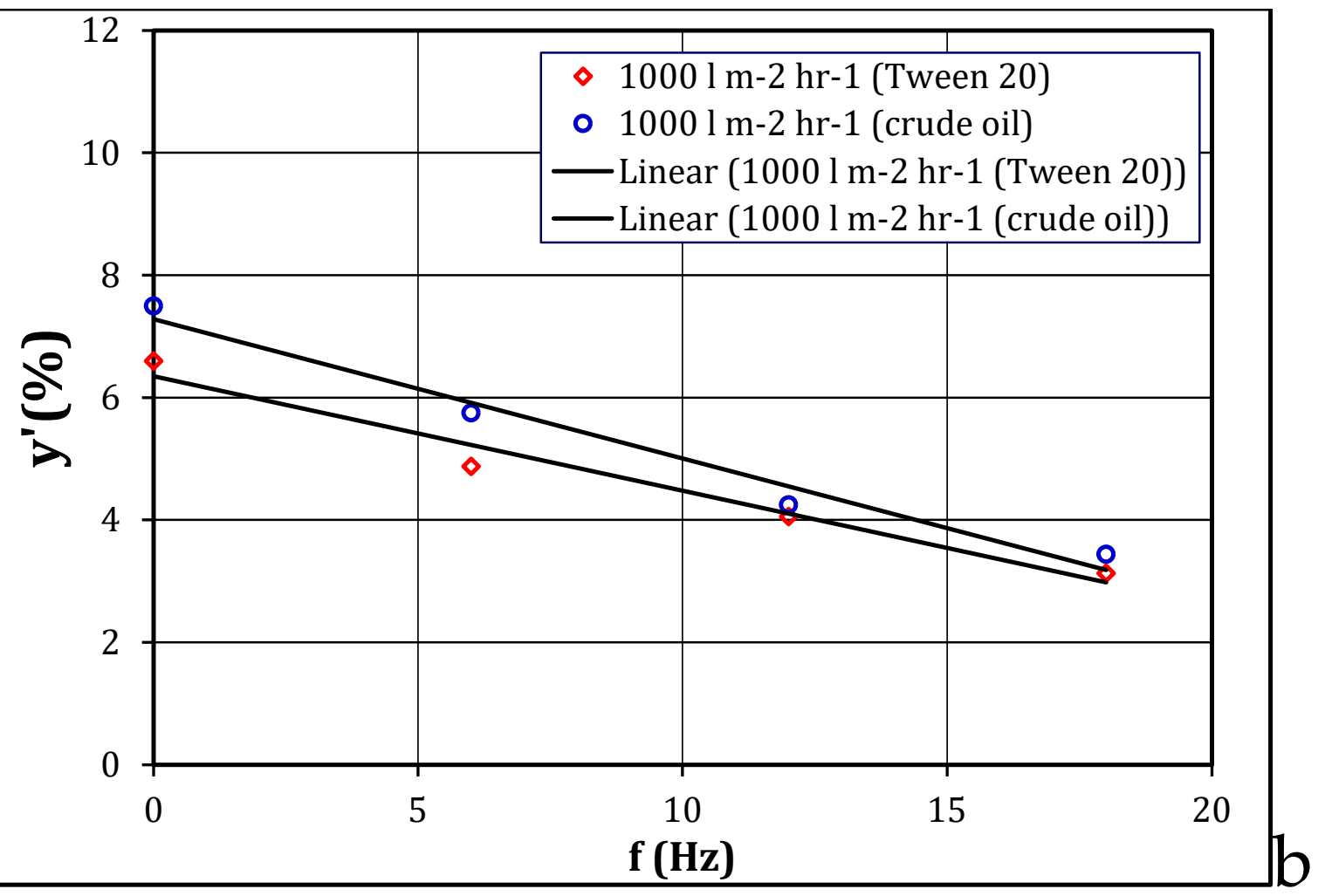

Figure 7. Impact of oscillation frequency, $f(H Z)$, on the pore blockage area, $y^{\prime}$, in percentage. Stable vegetable oil droplets (stabilized by Tween 20) \& crude oil droplets at (a) $2001 / \mathrm{m}^{2} \mathrm{~h}$ (b) 1,000 1/m²h.

Table 1. Number of crude oil drops (30 American Petroleum Institute) and concentration of oil in the feed and permeate obtained at various frequencies of oscillation and $400 \mathrm{l} \mathrm{m}^{-2} \mathrm{hr}^{-1}$ flux rate.

\begin{tabular}{cccc}
\hline Frequency (Hz) & $\begin{array}{c}\text { No of drops per } \mathbf{0 . 4} \mathbf{~ m l} \\
\text { sample }\end{array}$ & $\begin{array}{c}\text { Concentration of crude } \\
\text { oil } \\
\text { in the feed (ppm) }\end{array}$ & $\begin{array}{c}\text { Concentration of crude } \\
\text { oil }\end{array}$ \\
\hline 25 & 1020 & 400 & 5 \\
21 & 1606 & 400 & 7 \\
0 & 5092 & 400 & 21 \\
\hline
\end{tabular}

Table 1 shows number of crude oil drops in the permeate and permeate concentration obtained at different shear rates. It is clear that both number of drops in the permeate and crude oil concentration in the permeate were influenced by the applied shear. No of drops and crude oil concentration reduced with the applied shear rate.

\section{CONCLUSIONS}

An analytical solution has been developed which allows to calculate the velocity and shear rate distribution in the vicinity of the oscillating membrane and on the membrane surface itself. It is shown that the oscillations result in creation of a lift force, which acts in opposite direction as compared with drag force. This results in lower number of oil droplets reaching the oscillating membrane, and hence, less oil droplet penetrating into the permeate (higher 
rejections) and lower membrane fouling. The analytical study was validated against the experimental results, which proves that oscillation of membrane reduced the concentration of the oil droplets in permeate and reduce the membrane fouling. This reduction in the oil droplets concentration in the permeate was found to be a linear function of oscillating frequency of the membrane. The oscillations reduce the blockage of pores, the greater the shear rate intensity, lesser pore blockage was noticed.

Acknowledgments: V. Starov acknowledge the financial support from European Space Agency (MAP EVAPORATIOON project) and Marie Curie NanoPaint Project, European Science Foundation.

\section{NOMENCLATURE:}

A Amplitude of oscillation (m)

$\mathrm{Z}(\mathrm{y}, \mathrm{t})$ Instantaneous displacement of an immersed oscillating membrane along z-axis (m)

$\mathrm{t} \quad$ Time $(\mathrm{s})$

$\mathrm{V}_{\mathrm{z}} \quad$ Velocity of the fluid in $\mathrm{z}$ direction $(\mathrm{m} / \mathrm{s})$

y Lateral coordinates $(\mathrm{m})$

$\mathrm{z} \quad$ Directional Coordinate $(\mathrm{m})$

\section{Greek Symbols}

$\begin{array}{ll}\gamma & \text { Shear rate }(1 / \mathrm{s}) \\ \gamma_{\mathrm{s}} & \text { Shear rate at membrane surface }(1 / \mathrm{s}) \\ \mu & \text { Fluid dynamic viscosity }(\mathrm{kg} / \mathrm{ms}) \\ v & \text { Fluid kinematic viscosity }\left(\mathrm{m}^{2} / \mathrm{s}\right) \\ \varrho & \text { Fluid density }\left(\mathrm{kg} / \mathrm{m}^{3}\right) \\ \omega & \text { Angular Frequency }(\mathrm{rad} / \mathrm{s}) \\ \mathrm{i} & \sqrt{-1} \\ \Re \mathrm{e} & \text { Real part }\end{array}$

\section{LIST OF ABBREVIATIONS}

MF

NF

Microfiltration

Nano Filtration

RD

Rotating Disk system

$\mathrm{RO}$

Reverse Osmosis

RMF

TMP

Rotating Membrane Filter system

UF

VHFM

Trans Membrane Pressure

VSEP

Ultrafiltration

Vibrating Hollow Fiber Module System

Vibratory Shear-Enhanced

Processing System 


\section{Appendix}

Solution of the Eq. (1) is obtained using (a) a method of separation variables and (b) solution is tried in complex variable form, but in the end the real part of the deduced solution satisfies the initial equation and boundary conditions (2) and (3).

Solution of Eq. (1) is presented in the following form

$$
V_{z}=\Re f_{1}(t) f_{2}(y)
$$

Substitution into Eq. (1) and separating variable results in:

$$
\frac{f_{1}^{\prime}(t)}{f_{1}(t)}=v f_{2}^{\prime \prime}(y) / f_{2}(y)
$$

The left- hand site of the latter equation depends on time only while the right-hand site on y only. The latter is possible only if both sides are constants. Having in mind that both sides should be oscillatory functions of $\omega$, this constant is equal to $i \omega$, where $i$ is the imaginary unit. The latter results in the following two equations

$$
\begin{gathered}
\frac{f_{1}^{\prime}(t)}{f_{1}(t)}=i \omega \\
\frac{v f_{2}^{\prime \prime}(y)}{f_{2}(y)}=i \omega
\end{gathered}
$$

Solution of these equations is as follows

$f_{1}(t)=e^{i \omega}=\cos \omega t+i \sin \omega t$

$f_{2}(y)=A_{1} e^{(\alpha+i \alpha) y}+A_{2} e^{(-\alpha-i \alpha) y}=A_{1} e^{\alpha y}(\cos \alpha y+i \sin \alpha y)+A_{2} e^{-\alpha y}(\cos \alpha y-i \sin \alpha y)$

(A3)

where $A_{1}$ and $A_{2}$ are integration constants. From the condition (3) we conclude that $\mathrm{A}_{1}=0$, otherwise the solution does not tend to zero at $\mathrm{y}$ tents to infinity. From the condition (2) we conclude that $A_{2}=A \omega$. Hence,

$$
f_{2}(y)=A \omega e^{-\alpha y}(\cos \alpha y-i \sin \alpha y)
$$

Substitution of expressions (A2) and (A4) into Eq.(A1) results in solution given by Eq. (4).

\section{REFERENCES}

[1] M. Cheryan, N. Rajagopalan, Membrane processing of oily streams. Wastewater treatment and waste reduction, J. Memb. Sci. 151 (1998) 13-28.

[2] L.-G. Faksness, P.G. Grini, P.S. Daling, Partitioning of semi-soluble organic compounds between the water phase and oil droplets in produced water, Mar. Pollut. Bull. 48 (2004) 731-742.

[3] A. Fakhru'l-Razi, A. Pendashteh, L.C. Abdullah, D.R.A. Biak, S.S. Madaeni, Z.Z. Abidin, Review of technologies for oil and gas produced water treatment, J. Hazard. Mater. 170 (2009) 530-551.

[4] S. Jiménez, M.M. Micó, M. Arnaldos, F. Medina, S. Contreras, State of the art of produced water treatment, Chemosphere. 192 (2018) 186-208.

[5] M. Rezakazemi, A. Khajeh, M. Mesbah, Membrane filtration of wastewater from gas and oil production, Environ. Chem. Lett. 16 (2018) 367-388.

[6] S. Dezhi, J.S. Chung, D. Xiaodong, Z. Ding, Demulsification of water-in-oil emulsion by wetting coalescence materials in stirred-and packed-columns, Colloids Surfaces A Physicochem. Eng. Asp. 150 (1999) 69-75.

[7] J.S. Eow, M. Ghadiri, A.O. Sharif, T.J. Williams, Electrostatic enhancement of coalescence of water droplets in oil: a review of the current understanding, Chem. Eng. J. 84 (2001) 173-192.

[8] A. Partovinia, F. Naeimpoor, Phenanthrene biodegradation by immobilized microbial consortium in 
polyvinyl alcohol cryogel beads, Int. Biodeterior. Biodegradation. 85 (2013) 337-344.

[9] A. Partovinia, F. Naeimpoor, Comparison of phenanthrene biodegradation by free and immobilized cell systems: formation of hydroxylated compounds, Environ. Sci. Pollut. Res. 21 (2014) 5889-5898.

[10] Y. Zhu, D. Wang, L. Jiang, J. Jin, Recent progress in developing advanced membranes for emulsified oil/water separation, NPG Asia Mater. 6 (2014) e101--e101.

[11] K.L. Jepsen, M.V. Bram, S. Pedersen, Z. Yang, Membrane fouling for produced water treatment: A review study from a process control perspective, Water. 10 (2018) 847.

[12] S. Widodo, D. Ariono, K. Khoiruddin, A.N. Hakim, I.G. Wenten, Recent advances in waste lube oils processing technologies, Environ. Prog. Sustain. Energy. 37 (2018) 1867-1881.

[13] R.W. Baker, Membrane technology and applications, John Wiley \& Sons, 2012.

[14] A. Wachinski, Membrane processes for water reuse, McGraw Hill Professional, 2012.

[15] M. Padaki, R.S. Murali, M.S. Abdullah, N. Misdan, A. Moslehyani, M.A. Kassim, N. Hilal, A.F. Ismail, Membrane technology enhancement in oil--water separation. A review, Desalination. 357 (2015) 197207.

[16] A.G. Fane, C. Tang, R. Wang, Membrane technology for water: microfiltration, ultrafiltration, nanofiltration, and reverse osmosis, Treatise Water Sci. (2011).

[17] J.W. Patterson, Industrial wastewater treatment technology, (1985).

[18] T. Bilstad, E. Espedal, Membrane separation of produced water, Water Sci. Technol. 34 (1996) 239-246.

[19] S. Huang, R.H.A. Ras, X. Tian, Antifouling membranes for oily wastewater treatment: Interplay between wetting and membrane fouling, Curr. Opin. Colloid Interface Sci. 36 (2018) 90-109.

[20] F.F. Nazzal, M.R. Wiesner, Microfiltration of oil-in-water emulsions, Water Environ. Res. 68 (1996) 1187-1191.

[21] J.M. Pope, S. Yao, A.G. Fane, Quantitative measurements of the concentration polarisation layer thickness in membrane filtration of oil-water emulsions using NMR micro-imaging, J. Memb. Sci. 118 (1996) 247-257.

[22] R.G. Holdich, I.W. Cumming, I.D. Smith, Crossflow microfiltration of oil in water dispersions using surface filtration with imposed fluid rotation, J. Memb. Sci. 143 (1998) 263-274.

[23] I.W. Cumming, R.G. Holdich, I.D. Smith, The rejection of oil by microfiltration of a stabilised kerosene/water emulsion, J. Memb. Sci. 169 (2000) 147-155.

[24] A. Ullah, V.M. Starov, M. Naeem, R.G. Holdich, Microfiltration of deforming oil droplets on a slotted pore membrane and sustainable flux rates, J. Memb. Sci. 382 (2011) 271-277.

[25] A. Ullah, M. Habib, S.W. Khan, M.I. Ahmad, V.M. Starov, Membrane oscillation and oil drop rejection during produced water purification, Sep. Purif. Technol. 144 (2015) 16-22.

[26] A. Ullah, R.G. Holdich, M. Naeem, V.M. Starov, Stability and deformation of oil droplets during microfiltration on a slotted pore membrane, J. Memb. Sci. 401 (2012) 118-124.

[27] S. Lee, Y. Aurelle, H. Roques, Concentration polarization, membrane fouling and cleaning in ultrafiltration of soluble oil, J. Memb. Sci. 19 (1984) 23-38.

[28] P. Lipp, C.H. Lee, A.G. Fane, C.J.D. Fell, A fundamental study of the ultrafiltration of oil-water emulsions, J. Memb. Sci. 36 (1988) 161-177.

[29] N. Nabi, P. Aimar, M. Meireles, Ultrafiltration of an olive oil emulsion stabilized by an anionic surfactant, J. Memb. Sci. 166 (2000) 177-188.

[30] B. Chakrabarty, A.K. Ghoshal, M.K. Purkait, Ultrafiltration of stable oil-in-water emulsion by polysulfone membrane, J. Memb. Sci. 325 (2008) 427-437.

[31] H. Falahati, A.Y. Tremblay, Flux dependent oil permeation in the ultrafiltration of highly concentrated and unstable oil-in-water emulsions, J. Memb. Sci. 371 (2011) 239-247.

[32] D. Lu, T. Zhang, J. Ma, Ceramic membrane fouling during ultrafiltration of oil/water emulsions: roles played by stabilization surfactants of oil droplets, Environ. Sci. Technol. 49 (2015) 4235-4244.

[33] T. Mohammadi, M. Kazemimoghadam, M. Saadabadi, Modeling of membrane fouling and flux decline in reverse osmosis during separation of oil in water emulsions, Desalination. 157 (2003) 369375. 
[34] H. Peng, K. Volchek, M. MacKinnon, W.P. Wong, C.E. Brown, Application on to nanofiltration to water management options for oil sands operation, Desalination. 170 (2004) 137-150.

[35] A. Ullah, S.W. Khan, A. Shakoor, V.M. Starov, Passage and deformation of oil drops through nonconverging and converging micro-sized slotted pore membranes, Sep. Purif. Technol. 119 (2013) 7-13.

[36] M. Chandler, A. Zydney, Effects of membrane pore geometry on fouling behavior during yeast cell microfiltration, J. Memb. Sci. 285 (2006) 334-342.

[37] S. Kuiper, R. Brink, W. Nijdam, G.J.M. Krijnen, M.C. Elwenspoek, Ceramic microsieves: influence of perforation shape and distribution on flow resistance and membrane strength, J. Memb. Sci. 196 (2002) 149-157.

[38] C.J.M. van Rijn, G.J. Veldhuis, S. Kuiper, Nanosieves with microsystem technology for microfiltration applications, Nanotechnology. 9 (1998) 343.

[39] S. Kuiper, C. van Rijn, W. Nijdam, O. Raspe, H. van Wolferen, G. Krijnen, M. Elwenspoek, Filtration of lager beer with microsieves: flux, permeate haze and in-line microscope observations, J. Memb. Sci. 196 (2002) 159-170.

[40] A. Ullah, M. Naeem, R.G. Holdich, V.M. Starov, S. Semenov, Microfiltration of deforming droplets, in: UK Colloids 2011, Springer, 2012: pp. 107-110.

[41] A. Ullah, R.G. Holdich, M. Naeem, V.M. Starov, Shear enhanced microfiltration and rejection of crude oil drops through a slotted pore membrane including migration velocities, J. Memb. Sci. 421 (2012) 6974.

[42] A. Ullah, V.M. Starov, M. Naeem, R.G. Holdich, S. Semenov, Filtration of suspensions using slit pore membranes, Sep. Purif. Technol. 103 (2013) 180-186.

[43] A. Ullah, R.G. Holdich, M. Naeem, S.W. Khan, V.M. Starov, Prediction of size distribution of crude oil drops in the permeate using a slotted pore membrane, Chem. Eng. Res. Des. 92 (2014) 2775-2781.

[44] A. Ullah, J. Ahmad, H. Khan, S.W. Khan, F. Zamani, S.W. Hasan, V.M. Starov, J.W. Chew, Membrane oscillation and slot (pore) blocking in oil--water separation, Chem. Eng. Res. Des. 142 (2019) 111-120.

[45] A. Ullah, K. Shahzada, S.W. Khan, V. Starov, Purification of produced water using oscillatory membrane filtration, Desalination 491 (2020) 114428.

[46] F. Zhao, Z. Li, X. Han, X. Zhou, Y. Zhang, S. Jiang, Z. Yu, X. Zhou, C. Liu, H. Chu, The interaction between microalgae and membrane surface in filtration by uniform shearing vibration membrane, Algal Research 50 (2020) 102012. 